Article

\title{
New Oils for Cosmetic O/W Emulsions: In Vitro/ In Vivo Evaluation
}

\author{
Giovana Damasceno Sousa *, Isabelle Moura Fittipaldi de Souza Dantas, Davi Pereira de Santana \\ and Leila Bastos Leal
}

Department of Pharmaceutical Sciences, Federal University of Pernambuco, Cidade Universitária, 50740-525 Recife, PE, Brazil; isabelle.fittipaldi@hotmail.com (I.M.F.d.S.D.);

davi.santana@nudfac.com.br (D.P.d.S.); leila.leal@nudfac.com.br (L.B.L.)

* Correspondence: giovana.sousa@nudfac.com.br

Received: 22 November 2017; Accepted: 26 December 2017; Published: 4 January 2018

\begin{abstract}
The aim of this study was to design new cosmetic formulations containing oils from catolé, licuri and spent coffee grounds, and to evaluate their immediate and long-term effects on skin barrier function and skin hydration. Nonionic oil-in-water $(\mathrm{o} / \mathrm{w})$ emulsions were prepared and physicochemically characterized. The effects of the formulations were assessed by volunteers and by measuring the water content of the epidermis (WCE) and transepidermal water loss (TEWL) both two hours and 20 days after daily application. The irritation potential was evaluated using three different methods: the Hen's egg chorioallantoic membrane test (HET-CAM); the observation of undesirable effects after skin formulation application, and by using the $\mathrm{L}^{*} \mathrm{a}^{*} \mathrm{~b}^{*}$ system to verify changes in skin coloring. The results obtained showed that the formulations containing $10 \%$ of these oils presented promising characteristics in the improvement of hydration and skin barrier function when compared to the baseline values and with the placebo cream. According to the sensory evaluation performed, all creams were found to have great acceptability.
\end{abstract}

Keywords: cosmetic creams; skin hydration; catolé; licuri; spent coffee grounds; Hen's egg chorioallantoic membrane test

\section{Introduction}

Skin moisturizing products generally seek to increase the water content of the stratum corneum, which depends on the barrier properties and the water gradient across the epidermis [1-3]. High water content in the stratum corneum and low transepidermal water loss (TEWL) are among the main features of healthy skin $[3,4]$.

The electrical capacitance method has been the most used among the several methods proposed for the determination of the water content of the epidermis (WCE), because it uses low frequency current and is little affected by temperature and relative humidity $[5,6]$.

The evaluation of TEWL is a well-established method in dermatology to assess the integrity of the skin barrier. When skin is damaged, its barrier function is impaired resulting in increased water loss $[7,8]$.

TEWL measurements allow observation of disturbances in the protective function of the skin at an early stage even before they are visible. Normal skin allows loss of water only in small amounts. In the case of many topical diseases or dry skin, the loss of water is much greater. The determination of TEWL is also an important support for investigating skin irritation that occurs due to various physical and chemical influences [9].

Licuri (Syagrus coronata) and catolé (Syagrus cearensis) are Brazilian palm trees from which oils containing a high content of saturated and unsaturated fatty acids (including oleic, linoleic, lauric and 
palmitic acid) are extracted. These fatty acids give emollient properties when incorporated into topical formulations [10,11].

From spent coffee grounds-a residue of coffee from homes and industries-it is possible to extract an oil with a high content of unsaturated fatty acids, predominantly linoleic acid, which makes it an alternative for cosmetic application [12].

Currently, polyunsaturated fatty acids have been used in the production of cosmetics to improve the appearance and health of the skin. Creams enriched with linoleic acid are especially related to reduction of dryness and problems of desquamation, thus providing brightness and softness to the skin [1].

Saturated and unsaturated fatty acids are in the natural composition of said oils giving them emollient properties when incorporated into dermocosmetic formulations. Consequently, it is of great importance to investigate the characteristics of these oils, seeking to demonstrate their moisturizing properties and to use these oils as new ingredients with proven efficacy and safety.

\section{Materials and Methods}

\subsection{Test Products}

Nonionic o/w creams containing 10\% weight/weight $(w / w)$ of oils from licuri (LIC Oil Cream), catolé (CAT Oil Cream), spent coffee grounds (SCOF Oil Cream), sweet almonds (SwA Oil Cream), and one formulation without any oil (No Oil cream) were prepared. Sweet almond oil was used as a positive control. To prepare the creams, the oily and aqueous phases were heated separately to $70 \pm 5{ }^{\circ} \mathrm{C}$, maintaining stirring at $1000 \mathrm{rpm}$ for $30 \mathrm{~min}$, then the oily phase was added to the aqueous phase and the system was mixed with constant agitation until the temperature reached $25^{\circ} \mathrm{C}$. The carbomer was neutralized using a sodium hydroxide $20 \%(w / v)$ solution. Catolé and licuri oil were extracted from nuts using a hydraulic press. The spent coffee grounds oil was extracted through a Soxhlet extractor.

The compositions of all formulations are shown in Table 1.

Table 1. Composition of the creams.

\begin{tabular}{cccccc}
\hline \multicolumn{7}{c}{ Formulations $(w / w)$} \\
\hline & No Oil Cream & CAT Oil Cream & SCOF Oil Cream & LIC Oil Cream & SwA Oil Cream \\
\hline Catolé oil & - & 10 & - & - & - \\
Licuri oil & - & - & 100 & $\overline{10}$ & - \\
Spent coffee oil & - & - & - & $\overline{10}$ \\
Sweet almond oil & - & - & 1.5 & 1.5 & 1.5 \\
Sorbitan oleate & 1.5 & 3.5 & 3.5 & 3.5 & 3.5 \\
Polysorbate 80 & 3.5 & 0.6 & 0.6 & 0.6 & 0.6 \\
Carbomer & 0.6 & 0.1 & 0.1 & 0.1 & 0.1 \\
Butylhydroxytoluene & 0.1 & 0.01 & 0.01 & 0.01 & 0.01 \\
Mixed fruit essence & 0.01 & $100 \mathrm{~g}$ & $100 \mathrm{~g}$ & $100 \mathrm{~g}$ & $100 \mathrm{~g}$ \\
Water q.s. & $100 \mathrm{~g}$ & & & & \\
\hline
\end{tabular}

\subsection{Physicochemical Characterization of the Creams}

The $\mathrm{pH}$ of the formulations was determined by the $\mathrm{pH} 21 \mathrm{pH}$ meter (Hanna, Woonsocket, RI, USA). The viscosity and rheological properties of the creams were determined at ambient temperature using the Digital Viscometer (Rheology (International) Shannon, County Clare, Ireland). The size distribution was measured by light scattering using the Zetasizer ${ }^{\mathrm{TM}}$ Nano-ZS90 (Malvern Instruments, Malvern, UK). All samples were analyzed by dilution 1:100 with water.

\subsection{Subjects}

A total of 30 healthy female subjects, $18-40$ years old and having Fitzpatrick skin types II, III, and IV, participated in this study after having given their written informed consent. The exclusion criteria 
were the presence of any dermatitis or other skin or allergic diseases and a smoking habit. Volunteers were instructed not to apply any topical formulations on the test sites for two days before and during the study.

\subsection{Study Design}

The moisturizing power of formulations containing the catolé, licuri and spent coffee grounds was compared to a placebo formulation and the same formulation containing sweet almond oil (SwA Oil Cream). The region selected for the studies was the lower middle portion of the forearms of the volunteers.

The two forearms were subdivided into three regions $\left(16 \mathrm{~cm}^{2}\right)$, where $0.1 \mathrm{~g}$ of the formulations containing oils from catolé, licuri, spent coffee grounds, sweet almonds and the placebo formulation were applied, a control area was also evaluated. These regions and the formulations applied therein were randomized among the volunteers in order to minimize the differences between the analyses [6].

The measurements were carried out in an air-conditioned room, with an ambient temperature of $25 \pm 2{ }^{\circ} \mathrm{C}$ and relative humidity of $50 \pm 5 \%$. The volunteers stayed $15 \mathrm{~min}$ in this room before the measurements.

The study was submitted and approved by the Research Ethics Committee of the Federal University of Pernambuco/Brazil, under registration N ${ }^{\circ}$ 167/11—SISNEP FR—417180 and 16847813.7.0000.5208.

\subsection{Evaluation of Effects after One Application}

For the determination of the immediate effects, the formulations were applied to the forearms of the volunteers, being measured before (baseline) and after $2 \mathrm{~h}$ of the single application.

\subsection{Study of Long-Term Efficacy}

For the long-term study, the volunteers took home the formulations that were applied daily for a period of 20 days. The formulations were given to the volunteers in a randomized and anonymous fashion. After 20 days, the volunteers returned to the laboratory to perform new measurements.

The volunteers were adequately instructed in terms of the amount to be applied of each formulation in their specific region.

\subsection{Skin Water Content and TEWL Measurements}

The water content of the epidermis and transepidermal water loss for all creams was performed with a Corneometer CM 825 and a Tewameter TM300 (Courage and Khazaka Electronic GmbH, Cologne, Germany). The measuring principle of the TEWL is based on Fick's diffusion law, indicating the quantity being transported per area and period of time, the TEWL value is expressed in $\mathrm{g} / \mathrm{m}^{2} \mathrm{~h}$. The values of WCE considered are the mean of ten measurements on adjacent sites of the forearm expressed as arbitrary units (UA) $[2,13,14]$.

Ten measurements were made in each region of the volunteers' forearms, and the mean values obtained were calculated. The number of measurements made was determined according to the size of the region studied, in order to ensure that the whole site was evaluated.

\subsection{Irritant Potential Analysis}

For the HET-CAM, saline solution $(0.9 \% \mathrm{NaCl} w / v)$ and $0.1 \mathrm{~N}$ sodium hydroxide $(\mathrm{NaOH})$ were used as a negative and positive control, respectively. All creams were diluted 1:1 with $0.9 \% \mathrm{NaCl}$. For each formulation tested, four fresh, fertile Leghorn eggs were used. The eggs were incubated at $37 \pm 0.5{ }^{\circ} \mathrm{C}$ with a relative humidity of $65 \pm 2 \%$ for 10 days. On the tenth day, the shell membrane was removed, exposing the chorioallantoic membrane (CAM). Visual analysis was used to verify if the CAM was suitable to test, then $300 \mu \mathrm{L}$ of each formulation was placed on the CAM surface. After $20 \mathrm{~s}$, the formulation was removed with saline solution. The CAM was observed under a 
magnifying glass for 5 min to determine the occurrence of any irritation effects in the CAM blood vessels (vascular lysis, hemorrhage, or coagulation). The vascular effects were observed according to the criteria described in the Protocol ICCVAM HET-CAM test method. Each formulation was classified according to the scores: $0-0.99$ corresponding to nonirritant; $1.00-4.99$ corresponding to slightly irritant; 5.00-8.99 corresponding to moderately irritant (MI); and 9.00-21.00 corresponding to severely irritant (SI) [15].

The CM-700d Spectrophotometer (Konica Minolta, Tokyo, Japan), using the L*a*b* system color was used to assess the potential irritation of the formulations by verifying possible changes in skin color [16].

\subsection{Sensorial Analysis}

To evaluate the acceptability of all creams, a questionnaire was completed by each volunteer, and assessed sensory attributes such as texture, odor, spreadability, and tackiness using a scale from 1 to 10.

\subsection{Statistical Analysis}

The results are expressed as means $\pm \mathrm{SD}$ of at least three values. The difference between the measurements was statistically evaluated with the analysis of variance (ANOVA). Data statistical significance was fixed at $p<0.05$.

\section{Results and Discussion}

\subsection{Physicochemical Characterization of the Creams}

Concerning the macroscopic characteristics, all creams appeared white, glossy, and as semimobile emulsions. The $\mathrm{pH}$ values, apparent viscosity, and droplet size are shown on Table 2.

Table 2. $\mathrm{pH}$, apparent viscosity, and droplet size values for the creams (Mean \pm S.D.).

\begin{tabular}{cccc}
\hline Formulation & $\mathbf{p H}$ & Apparent Viscosity $(\mathbf{P a} \cdot \mathbf{s})$ & Droplet Size $(\boldsymbol{\mu m})$ \\
\hline No Oil Cream & $6.01 \pm 0.2$ & $24.95 \pm 1.3$ & $0.41 \pm 0.07$ \\
CAT Oil Cream & $5.92 \pm 0.1$ & $23.66 \pm 1.1$ & $0.51 \pm 0.09$ \\
LIC Oil Cream & $5.96 \pm 0.1$ & $24.55 \pm 1.9$ & $0.46 \pm 0.10$ \\
SCOF Oil Cream & $6.03 \pm 0.1$ & $23.84 \pm 1.4$ & $0.52 \pm 0.09$ \\
SwA Oil Cream & $6.06 \pm 0.1$ & $24.05 \pm 2.1$ & $0.48 \pm 0.08$ \\
\hline
\end{tabular}

The results obtained reveal $\mathrm{pH}$ and viscosity values acceptable for cutaneous application, and no significant differences were observed between these values for all creams $(p<0.05)$. As observed in Table 2, the mean droplet size was between 0.41 and $0.52 \mu \mathrm{m}$, characteristic values of emulsions, and without large size variation.

The $\mathrm{pH}$ should ensure the stability of the ingredients of a formulation, their efficacy and safety, as well as being compatible with the intended route of administration. The formulations studied had the $\mathrm{pH}$ adjusted to slightly acidic values, as this was the ideal $\mathrm{pH}$ range (5.5-6.5) for the proposed purposes, and also to optimize the viscosity of the polymer used. The formulations showed well-formed droplets with small size variation, thus indicating greater stability of the emulsified system [11].

The flow curves (Figure 1) show that all formulations presented non-Newtonian behavior of the pseudoplastic type, where the viscosity of the fluid decreases with increasing shear rate.

The pseudoplastic behavior presented by all formulations is a desirable feature for emulsions since viscosity values are reduced with increased shear stress, facilitating application to the skin [17]. This type of behavior is frequent in formulations containing natural or synthetic gums and polymers [18]. Thus, all the creams designed within this work were appropriate for skin application. 


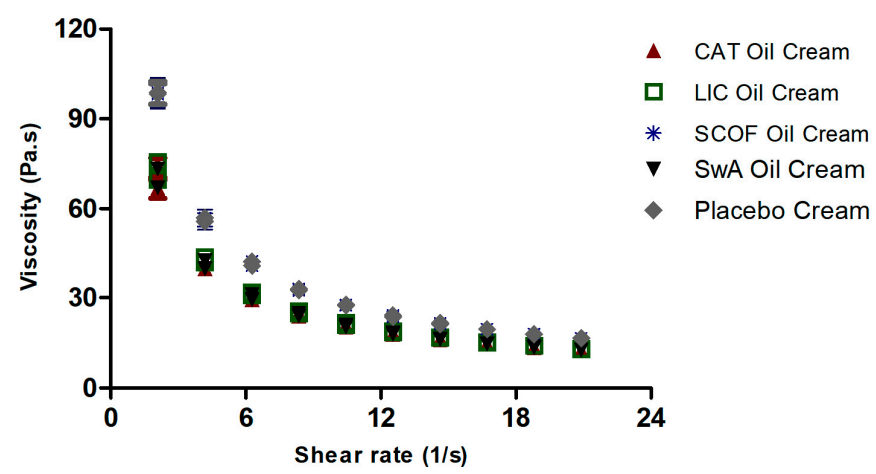

Figure 1. Flow curves for all creams.

\subsection{Evaluation of Skin Hydration and Barrier Function}

The results obtained (Figure 2) showed that after two hours of application, the creams containing oils from licuri, catolé, spent coffee grounds, and sweet almonds significantly increase the epidermis water content $(p<0.05)$. The effect was more evident for the formulations containing oils from licuri and catolé.

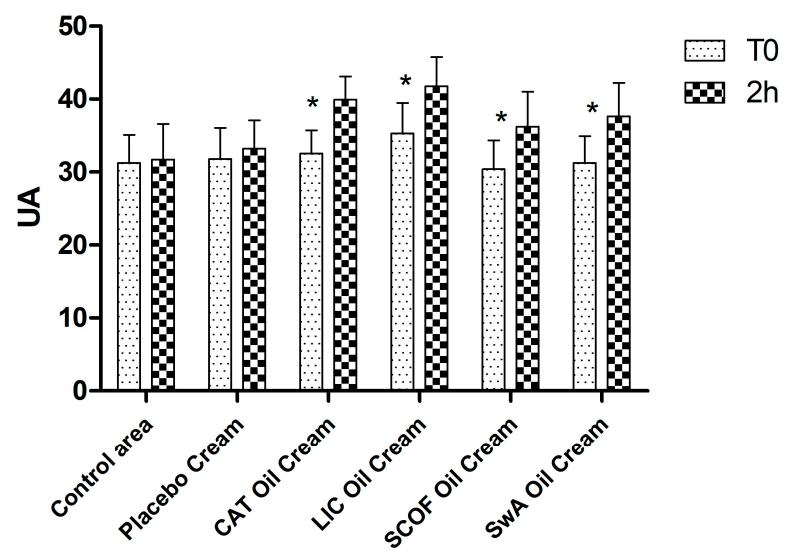

Figure 2. Water content of the stratum corneum before (baseline values) and $2 \mathrm{~h}$ after the application of the formulations. ${ }^{*}$ Statistically significantly higher compared to baseline values $(p<0.05)$.

All the formulations studied produced a significant increase in stratum corneum moisture $(p<0.05)$ 20 days after daily application, when compared with the baseline values and with the placebo cream (Figure 3).

Figure 4 shows TEWL was significantly reduced after $2 \mathrm{~h}$ application and 20 days after daily application, which may indicate an improved protection of the skin barrier function, only with formulations containing these oils under study $(p<0.05)$.

The evaluation of the immediate effects of cosmetic products is important because it allows verification of the action of these products on the skin soon after their application. Likewise, evaluating a dermocosmetic product under the actual conditions of use allows the scientific elucidation of its long-term effects on the skin.

Skin dryness is the most prevalent skin health problem globally and can impact the perception of well-being and quality of life [19]. Additionally, dry skin, redness, and cracking may increase the possibility of an infection because the skin barrier is damaged $[20,21]$. The measurement of hydration in the surface layer of the skin and TEWL gives important information on the biophysical properties and function of the skin barrier. 


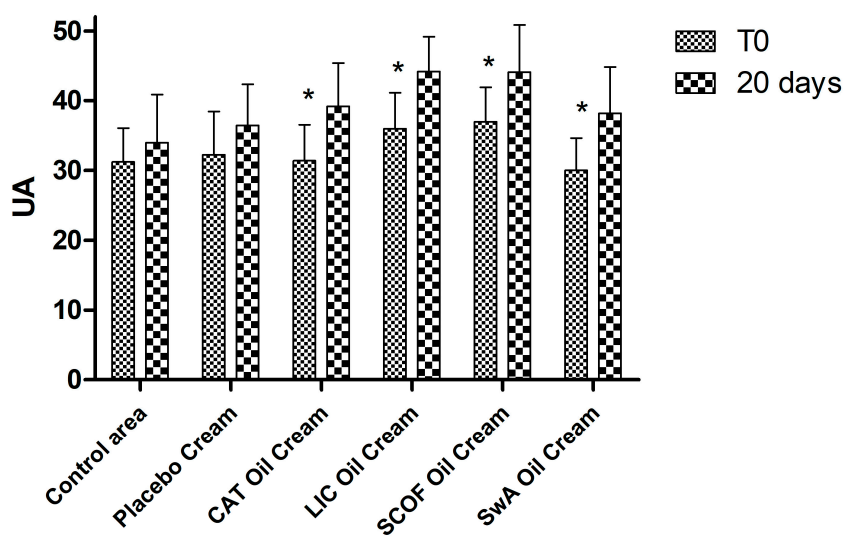

Figure 3. Water content of the stratum corneum before (baseline values) and 20 days after daily application of the formulations. * Statistically significantly higher compared to baseline values $(p<0.05)$.

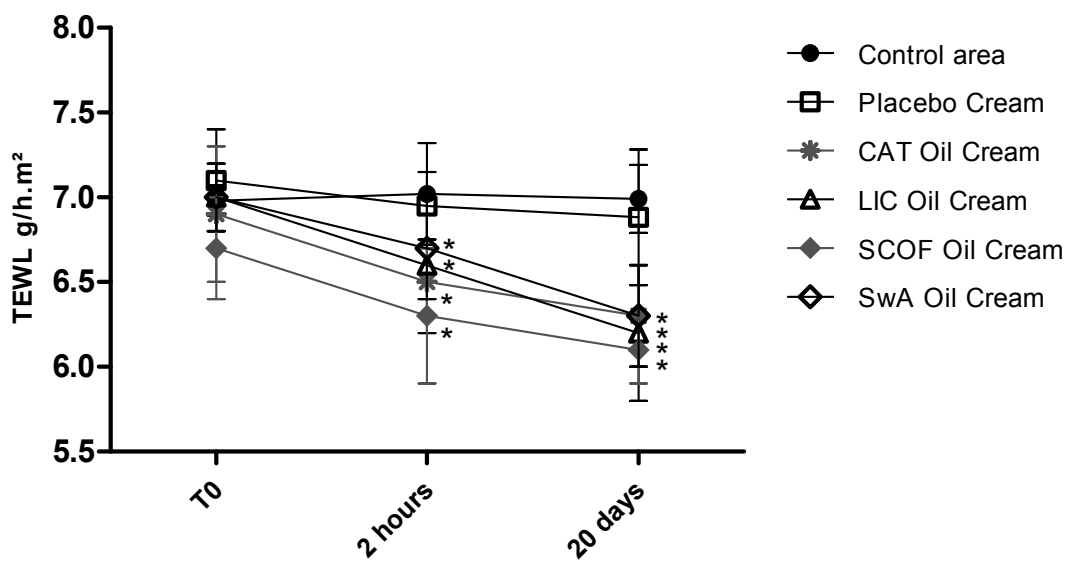

Figure 4. Values of transepidermal water loss (TEWL) during 20 days.

The WCE results were expressed in arbitrary units and values below 30 represent very dry skin, between 30 and 45, moderately dry skin and values greater than 45 , sufficiently hydrated skin [22]. Therefore, it is perceived that the use of the formulations containing the oils under study contributed in a significant way to improve the hydration of the skin of the volunteers, who, in general, presented as dry skin.

As know, there is a correlation between stratum corneum (SC) hydration and TEWL values; lower TEWL indicates better skin barrier function [23]. In our experiments, all creams containing oils from catolé, licuri and spent coffee grounds increased Corneometer and decreased Tewameter measurements $2 \mathrm{~h}$ and 20 days after daily application, suggesting skin hydration.

There was no significant difference between the hydration profiles of the formulations containing the evaluated oils, although their composition is different, licuri and catolé oils have higher percentages of saturated fatty acids, primarily lauric acid [24]. The coffee grounds oil has a predominance of unsaturated fatty acids, including $44.7 \%$ linoleic acid [12].

The sweet almond oil was used as a reference, because it has recognized moisturizing and toning properties of dry skin [25], as confirmed in our study since the cream containing SwA Oil also increased WCE measurements.

Lipids play a significant role in the skin, fatty acids like linoleic, oleic, and lauric acid are naturally present in the skin triglycerides. Especially unsaturated fatty acids such as linoleic acid, which has recognized potential in terms of skin hydration by helping to maintain skin elasticity and combat its premature aging [1]. However, we can infer that in this case, the improvement on hydration and 
skin barrier function probably occurred by hindering water permeation through the skin. This means spreading an occlusive oily layer onto the stratum corneum surface or by supplementation of skin lipids, and there's no specific relationship to the fatty acid compositions of each oil.

Previous literature shows that formulations containing oil from spent coffee grounds have multiple skin benefits on barrier function and skin hydration [12] when compared to baseline values, corroborating the results obtained in this study.

\subsection{Irritant Potential}

The HET-CAM is used to provide qualitative information on the potential effects occurring in the conjunctiva region following exposure to a substance. This assay has been widely used to assess the irritant potential of topical medicines and cosmetics that may come in contact with the eyes [10]. According to our results (Table 3) all creams were classified as nonirritant, suggesting that they are safe for topical application, including in the face.

Table 3. Hen's egg chorioallantoic membrane test (HET-CAM) results (mean \pm S.D.).

\begin{tabular}{ccc}
\hline \multirow{2}{*}{ Formulation } & \multicolumn{2}{c}{ HET-CAM Score } \\
\cline { 2 - 3 } & Score & Class \\
\hline No Oil Cream & $0.70 \pm 0.3$ & NOI \\
CAT Oil Cream & $0.75 \pm 0.3$ & NOI \\
LIC Oil Cream & $0.65 \pm 0.2$ & NOI \\
SCOF Oil Cream & $0.75 \pm 0.2$ & NOI \\
SwA Oil Cream & $0.50 \pm 0.3$ & NOI \\
0.1 N NaOH & $18.0 \pm 2.5$ & SEI \\
\hline
\end{tabular}

The results of color variation ( $\mathrm{a}^{*}$ parameter) did not shown statistically significant alterations $(p<0.05)$ for any of the tested creams, indicating that they did not promote irritation of the skin during the tests (Figure 5).

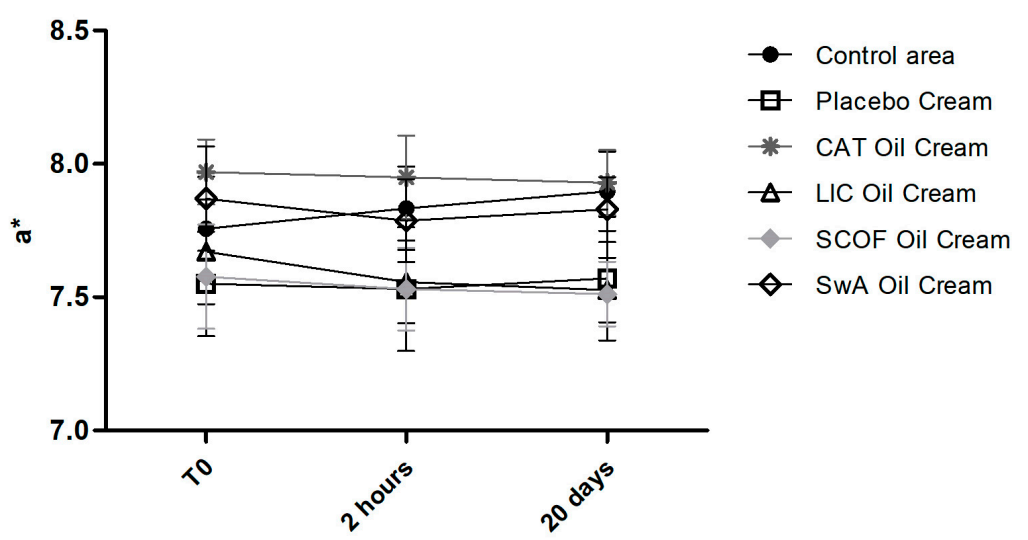

Figure 5. Colorimetric results in function of time after creams application.

\subsection{Sensorial Analysis}

According the results of the sensorial evaluation (Figure 6), all creams met consumer appeal and acceptance requirements. However, the volunteers could not verify differences between the formulations.

Sensory assessments are important because they show consumers' perception and acceptability of products. The creams presented good acceptability and the volunteers were able to perceive a positive effect in the use of the formulations, however, without differentiating those that contained oil and placebo. 


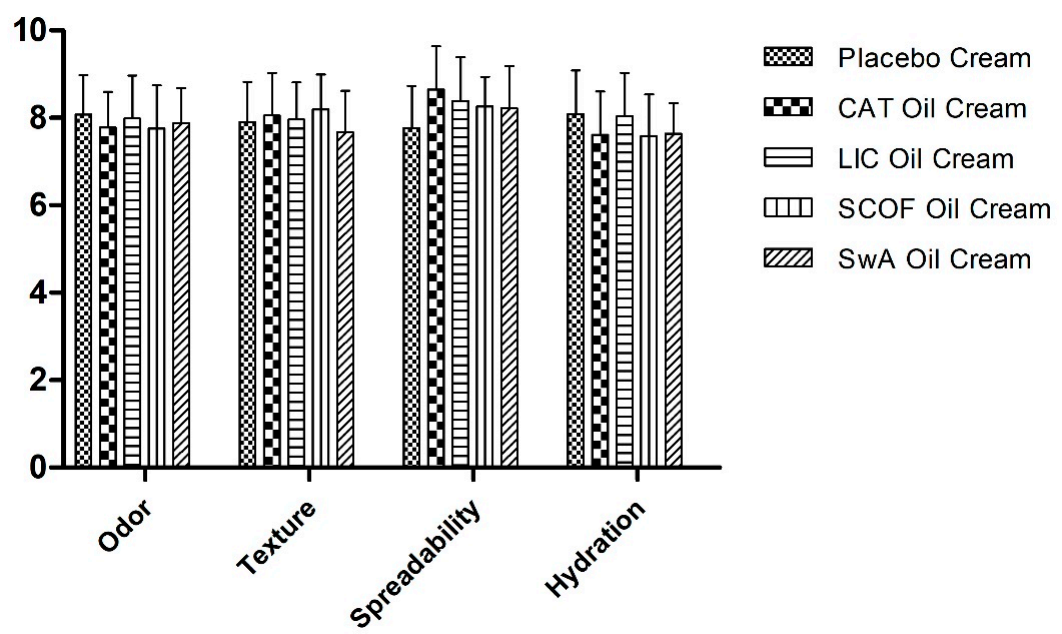

Figure 6. Sensorial evaluation.

This work showed that all creams containing these oils under study had significant hydration effects on the skin by increasing the water content of epidermis and on skin barrier function, which resulted in TEWL reduction when compared with the placebo and control area, and similar results when compared with formulations containing the positive control. This provides a sustainable, cheaper, and effective alternative to the oils of consecrated use in hydration and tonicity of the skin.

In conclusion, these results allow us to signal new vegetable oils with cosmetic applicability to the product chain of natural products with sustainable development.

Acknowledgments: The authors thank FACEPE and FECDA for financial support.

Author Contributions: Giovana Sousa and Isabelle Dantas did the practical activities. Giovana Sousa and Davi Santana analyzed the data. Giovana Sousa and Leila Leal wrote the paper.

Conflicts of Interest: The authors declare no conflicts of interest.

\section{References}

1. Boucetta, K.Q.; Charrouf, Z.; Derouiche, A.; Rahali, Y.; Bensouda, Y. Skin hydration in postmenopausal women: Argan oil benefit with oral and/or topical use. Prz. Menopauzalny 2014, 13, 280-288. [CrossRef] [PubMed]

2. Tichota, D.M.; Silva, A.C.; Lobo, J.M.; Amaral, M.H. Design, characterization, and clinical evaluation of argan oil nanostructured lipid carriers to improve skin hydration. Int. J. Nanomed. 2014, 9, 3855-3864. [CrossRef]

3. Roberts, M.S.; Bouwstra, J.; Pirot, F.; Falson, F. Skin hydration-a key determinant in topical absorption. In Dermatologic, Cosmeceutic, and Cosmetic Development: Therapeutic and Novel Approaches; Informa Healthcare: New York, NY, USA; London, UK, 2008; pp. 115-128.

4. Cheng, Y.; Dong, Y.; Dong, M.; Wang, C.; Sun, Y.; Su, N.; Liu, J.; Zheng, H.; Yang, X.; Li, J.; et al. Moisturizing and antisebum effect of cosmetic application on facial skin. J. Cosmet. Dermatol. 2007, 6, 172-177. [CrossRef] [PubMed]

5. Camargo Junior, F.B. Development of Cosmetic Formulations Containing Panthenol and Evaluation of Their Hydration Effects on Human Skin by Using Skin Bioengineering. Master's Thesis, University of São Paulo, São Paulo, Brazil, 2006.

6. Dal'Belo, S.E.; Rigo Gaspar, L.; Campos, B.G.; Maria, P. Moisturizing effect of cosmetic formulations containing Aloe vera extract in different concentrations assessed by skin bioengineering techniques. Skin Res. Technol. 2006, 12, 241-246. [CrossRef]

7. Schlupp, P.; Weber, M.; Schmidts, T.; Geiger, K.; Runkel, F. Development and validation of an alternative disturbed skin model by mechanical abrasion to study drug penetration. Results Pharma Sci. 2014, 31, 26-33. [CrossRef] [PubMed] 
8. Netzlaff, F.; Kostka, K.H.; Lehr, C.M.; Schaefer, U.F. TEWL measurements as a routine method for evaluating the integrity of epidermis sheets in static Franz type diffusion cells in vitro. Limitations shown by transport data testing. Eur. J. Pharm. Biopharm. 2006, 63, 44-50. [CrossRef] [PubMed]

9. Mündlein, M.; Valentin, B.; Chabicovsky, R.; Nicolics, J.; Weremczuk, J.; Tarapata, G.; Jachowicz, R. Comparison of transepidermal water loss (TEWL) measurements with two novel sensors based on different sensing principles. Sens. Actuators A Phys. 2008, 142, 67-72. [CrossRef]

10. Sousa, G.D.; Kishishita, J.; Aquino, K.A.; Presgrave, O.A.; Leal, L.B.; Santana, D.P. Biopharmaceutical Assessment and Irritation Potential of Microemulsions and Conventional Systems Containing Oil from Syagrus cearensis for Topical Delivery of Amphotericin B Using Alternative Methods. AAPS PharmSciTech 2016, 18, 1833-1842. [CrossRef] [PubMed]

11. Leal, L.B.; Sousa, G.D.; Seixas, K.B.; Souza, P.H.; Santana, D.P. Determination of the critical hydrophile-lipophile balance of licuri oil from Syagrus coronata: Application for topical emulsions and evaluation of its hydrating function. Braz. J. Pharm. Sci. 2013, 49, 167-173. [CrossRef]

12. Ribeiro, H.; Marto, J.; Raposo, S.; Agapito, M.; Isaac, V.; Chiari, B.G.; Lisboa, P.F.; Paiva, A.; Barreiros, S.; Simões, P. From coffee industry waste materials to skin-friendly products with improved skin fat levels. Eur. J. Lipid Sci. Technol. 2013, 115, 330-336. [CrossRef]

13. Tukhvatullina, D.; Béguin, A.; Pong, H.; Cabarbas, M.D.; Klokol, D.; Chan, M.K.; Wong, M.B. Evaluation of the in vivo cosmetic efficacy of the MFIII blue cell serum gel. One-and two-month test results. J. Cosmet. Dermatol. 2017, 1-10. [CrossRef]

14. Camargo Junior, F.B.; Gaspar, L.R.; Campos, P.M. Immediate and long-term effects of polysaccharides-based formulations on human skin. Braz. J. Pharm. Sci. 2012, 48, 547-555. [CrossRef]

15. Interagency Coordinating Committee on the Validation of Alternative Methods (ICCVAM). Current Validation Status of In Vitro Test Methods Proposed for Identifying Eye Injury Hazard Potential of Chemicals and Products; NIH Publication 10-7553; National Institute of Environmental Health Sciences: Research Triangle Park, NC, USA, 2010.

16. Pereira, T.A.; Guerreiro, C.M.; Maruno, M.; Ferrari, M.; Rocha-Filho, P.A. Exotic vegetable oils for cosmetic o/w nanoemulsions: In vivo evaluation. Molecules 2016, 21, 248. [CrossRef] [PubMed]

17. Morais, G.G.; Santos, O.D.; Masson, D.S.; Oliveira, W.P.; Filho, P.A. Development of O/W emulsions with Annatto Oil (Bixa orellana) containing liquid crystal. J. Dispers. Sci. Technol. 2005, 26, 591-596. [CrossRef]

18. Pianovski, A.R.; Vilela, A.F.; da Silva, A.A.; Lima, C.G.; da Silva, K.K.; Carvalho, V.F.; De Musis, C.R.; Machado, S.R.; Ferrari, M. Use of pequi oil (Caryocar brasiliense) in cosmetics emulsions: Development and evaluate of physical stability. Braz. J. Pharm. Sci. 2008, 44, 249-259. [CrossRef]

19. Nash, J.F.; Matts, P.J.; Ertel, K.D. Maintenance of healthy skin: Cleansing, moisturization, and ultraviolet protection. J. Cosmet. Dermatol. 2007, 6, 7-11. [CrossRef]

20. Arezki, N.R.; Williams, A.C.; Cobb, A.A.; Brown, M.B. Design, synthesis and characterization of linear unnatural amino acids for skin moisturization. Int. J. Cosmet. Sci. 2017, 39, 72-82. [CrossRef] [PubMed]

21. Kanlayavattanakul, M.; Rodchuea, C.; Lourith, N. Moisturizing effect of alcohol-based hand rub containing okra polysaccharide. Int. J. Cosmet. Sci. 2012, 34, 280-283. [CrossRef] [PubMed]

22. Courage \& Khazaka Eletronic GmbH. Information and Operating Instructions for the Derma Unit SSC 3; Courage \& Khazaka Eletronic GmbH: Cologne, Germany, 2010; 26p.

23. Jeong, C.B.; Han, J.Y.; Cho, J.C.; Suh, K.D.; Nam, G.W. Analysis of electrical property changes of skin by oil-in-water emulsion components. Int. J. Cosmet. Sci. 2013, 35, 402-410. [CrossRef] [PubMed]

24. Queiroga, R.D.R.E.; Maia, M.O.; Medeiros, A.N.; Costa, R.G.; Pereira, R.A.G.; Bomfim, M.A.D. Production and chemical composition of the milk from crossbred Moxotó goats supplemented with licuri or castor oil. R. Bras. Zootec. 2010, 39, 204-249. [CrossRef]

25. Ahmad, Z. The uses and properties of almond oil. Complement. Ther. Clin. Pract. 2010, 16, 10-12. [CrossRef] [PubMed]

(C) 2018 by the authors. Licensee MDPI, Basel, Switzerland. This article is an open access article distributed under the terms and conditions of the Creative Commons Attribution (CC BY) license (http:/ / creativecommons.org/licenses/by/4.0/). 